\title{
A PRODUÇÃO DISCENTE DO PROGRAMA DE PÓS-GRADUAÇÃO EM EDUCAÇÃO DA UNOESTE NO ANO DE 2012.
}

\author{
Genivaldo de Souza Santos ${ }^{1}$, Helena Farias de Barros² \\ ${ }^{1}$ Instituto Federal de São Paulo - IFSP, Birigui, SP, ${ }^{2}$ Universidade do Oeste Paulista - UNOESTE, Programa de Pós- \\ Graduação em Educação, Presidente Prudente, SP. E-mail:genivaldo@ifsp.edu.br.
}

\begin{abstract}
RESUMO
O presente artigo tem por objetivo dar continuidade ao estudo da produção discente do programa de Mestrado em Educação da Unoeste de 2012 (iniciado a partir de 2003). Os dados levantados foram extraídos dos resumos das dissertações defendidas no Programa ao longo desse ano e serão submetidos a procedimentos de análise quanti-qualitativos. As categorias de análise estabelecidas são: linhas de pesquisa; temáticas; instituições e populações envolvidas; abordagens e métodos. Pretende-se indagar e refletir sobre os fatores que acarretam possíveis aumentos ou diminuições da produção, as tendências da pesquisa educacional desenvolvida no Programa de Pós-Graduação em Educação da Unoeste, bem como as lacunas e aspectos inexplorados no conjunto das pesquisas.
\end{abstract}

Palavras-chave: Produção discente, Pós-graduação, Educação.

\section{THE POSTGRADUATE STUDENT PRODUCTION OF THE EDUCATION POST-GRADUATION PROGRAM OF UNOESTE IN THE YEAR OF 2012.}

\begin{abstract}
This article aims to continue the study of the student production Master's program in 2012 Unoeste Education (started from 2003). The collected data were extracted from the abstracts of dissertations in the program throughout the year and are subject to quantitative and qualitative analysis procedures. The established categories of analysis: lines of research; themes; institutions and populations involved; approaches and methods. It is intended to investigate and reflect on the factors that lead to possible increases or decreases in production, trends in educational research developed at the Graduate Program in Education Unoeste as well as the gaps and unexplored aspects in all the surveys.
\end{abstract}

Keywords: Student production, Post-graduate, Education. 


\section{INTRODUÇÃO}

O Programa de Pós-Graduação Stricto Sensu em Educação da Universidade do Oeste Paulista (Unoeste), com seu curso de Mestrado em funcionamento desde 1995, tem se consolidado por meio de sua produção científica, com a realização de inúmeras pesquisas, envolvendo temas educacionais de grande significação local e regional. Tais pesquisas, além de favorecerem o processo de reflexão crítica, têm oportunizado o desenvolvimento de ações com vistas à transformação da realidade educacional nos seus diferentes ambientes.

Esse trabalho de análise da produção discente deverá se constituir em um material de extrema importância para o processo de autoavaliação do programa e poderá oferecer subsídios para o delineamento dos novos projetos de pesquisa discente.

De modo geral, objetivamos analisar as dissertações do Programa, defendidas no período de 2012, com o intuito de mapear a distribuição das dissertações quanto as linhas de pesquisa, temática, instituições e população envolvidas, métodos e procedimentos de investigação utilizados e suas implicações.

\section{METODOLOGIA}

A pesquisa proposta se configura como quali-quantitativa. A natureza do objeto requer que as atenções se estendam aos aspectos quantitativos, porém, com clara intencionalidade da análise interpretativa do significado dos trabalhos elaborados. Analisar os fatos para compreendêlos é o grande interesse da investigação Não há preocupação com a explicação, isto é, com a busca de causas e efeitos.

Assim, com a avaliação que se deseja busca-se o seu significado mais amplo, tratando-se de um verdadeiro desafio que exige criatividade e subjetividades presentes e atuantes (PENNA FIRME, 2009). Para tanto serão analisados 21 (vinte e um) resumos de dissertações defendidas no Programa de Pós-Graduação em Educação da UNOESTE no período de 2012.

Os dados coletados serão submetidos a procedimentos quanti-qualitativos e as categorias de análise envolverão: linhas de pesquisa, temas, instituições, população alvo, procedimentos de investigação e direções assumidas na orientação metodológica das dissertações.

\section{REFERENCIAL TEÓRICO}

Nas duas últimas décadas, a avaliação, tanto a de cursos quanto a institucional, ganhou significação pelo seu papel elucidativo na definição de caminhos, articulação de ações, compreensão do alcance de políticas internas de diversas naturezas, entre outros.

No contexto avaliativo, por seu impacto emancipatório, a autoavaliação tem merecido atenção especial. De Sordi, citada por Masetto (2004, p. 30), argumenta que:

Avaliar implica o desejo de conhecer, tirar as máscaras, ato de entrega que não pode ser imposto simplesmente. Daí a defesa de processos de avaliação regidos pela adesão voluntária, que sinalizam na direção do compromisso com os resultados avaliativos, dando-lhes conseqüência. Avaliar não é um ato tópico (...) não visa à constatação da instantaneidade, mas a um processo que acompanha a existência mesma da Instituição.

O olhar externo não alcança, por exemplo, as singularidades de um Programa de Mestrado. Por isso, Masetto (2004) assegura que não basta sabermos o que a Capes espera de cada Programa. "Mais importante do que isso, para que pudéssemos traçar nossas próprias diretrizes, implementar nossos projetos institucionais, construir nossa identidade, era dar início a um processo de autoconhecimento" (p.16). 
Nessa perspectiva, Masetto (2004) reitera que mais do que atender as expectativas externas, é preciso termos clareza de nossos objetivos, do nosso projeto de pós-graduação e daquilo que nos identifica como Programa e que norteia nossas ações.

Uma importante via de autoconhecimento se abre quando se ouve o egresso. Paiva (2006) afirma que ouvir egressos significa dar voz ao ex-aluno, "estabelecendo conexões importantes que possam nortear um trabalho pedagógico fortalecedor de uma sociedade mais justa e igualitária" (p.18).

Nessa perspectiva, o conhecimento da história da Instituição ou do Programa é um patrimônio que potencializa as chances de êxito em passos futuros. Esse conhecimento, como esclarece Dias Sobrinho (2000), toma produtos e processos como componentes de um mesmo todo:

Toda avaliação que considera os processos de produção como essenciais necessariamente deve levar em conta os produtos, para fugir de qualquer abstracionismo. Condenável é considerar os produtos como entidades suficientes em si mesmos, sem a compreensão dos processos que os engendraram. (p.131)

No presente artigo, o objeto de estudo são as dissertações, produtos singulares que carregam as marcas do processo de construção.

\section{RESULTADOS}

\section{ANÁLISE DA TEMÁTICA}

A produção discente no ano de 2012 totalizou 21 (vinte e uma) dissertações, sendo 8 (oito) produções vinculadas à linha 1 - Instituição Educacional: Organização e Gestão e 13 (treze) produções vinculadas à linha 2 - Formação e Prática Pedagógica do Profissional Docente. Justificase a diferença no volume de produção entre as linhas devido ao maior número de docente (orientadores) na linha 2, que certamente reflete no item analisado.

Em relação a temática das dissertações produzidos no ano de 2012, tomamos como critério o título da dissertação, ainda respeitando os limites das linhas de pesquisa, categorizamos as temáticas da linha 1 em dois eixos, i) Gestão e ii) Gestão associada ao conhecimento institucionalizado. Em torno do eixo i, as pesquisas privilegiaram o espaço escolar, quer a gestão democrática e participativa (1), quer a relação da gestão com o espaço escolar (1), quer a relação da gestão com a justiça restaurativa (1), quer a relação da gestão em seus aspectos avaliativos (1) e, do o ponto de vista da coordenação pedagógica escolar (1).

Em menor número de produções, no eixo ii, a Gestão associada a conhecimento institucionalizado, assumiu como temática de análise a) o perfil empreendedor do curso de Administração (1); b) análise do projeto pedagógico do curso tecnológico de gestão comercial (1) e, c) a motivação como estratégia de qualidade (1).

Assumindo como referência a ementa desta linha de pesquisa, verificou-se uma coerência das produções em relação à sua proposição dentro da área de concentração.

Em relação à linha 2, categorizamos as temáticas em 4 (quatro) eixos, o de maior produção, foi denominado de i) Formação de saberes para o exercício da docência, associados à Geometria (1), Língua inglesa (1), uso de filme (1), formação para o uso das TICs (2), Educação Física (1) e uso das tecnologias assistivas (2). No eixo ii, denominado de Formação pedagógica em cursos de bacharelado, verificou-se a existência de uma produção ligada ao curso de Direiro. No Eixo iii, denominado Representações Sociais, verificou-se a existência de 2 (dois) trabalhos, um relacionado ao professor do século XXI e outro relacionado ao aluno. Por fim, no eixo iv denominado de Ação docente e Interdisciplinaridade, verificou-se a existência de um trabalho. 


\section{Análise das Instituições envolvidas}
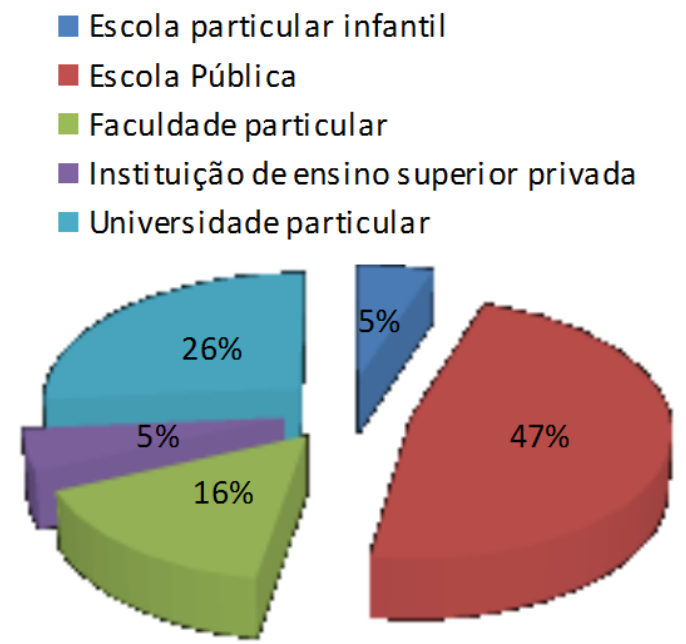

Gráfico 1. Instituições envolvidas

Analisando as instituições envolvidas na produção discente do ano de 2012, evidencia-se o seguinte quadro: Escola pública (47\%), Faculdade particular (16\%), Instituição de ensino superior privada (5\%), Universidade particular (26\%), Escola particular infantil (5\%).

\section{População envolvida}

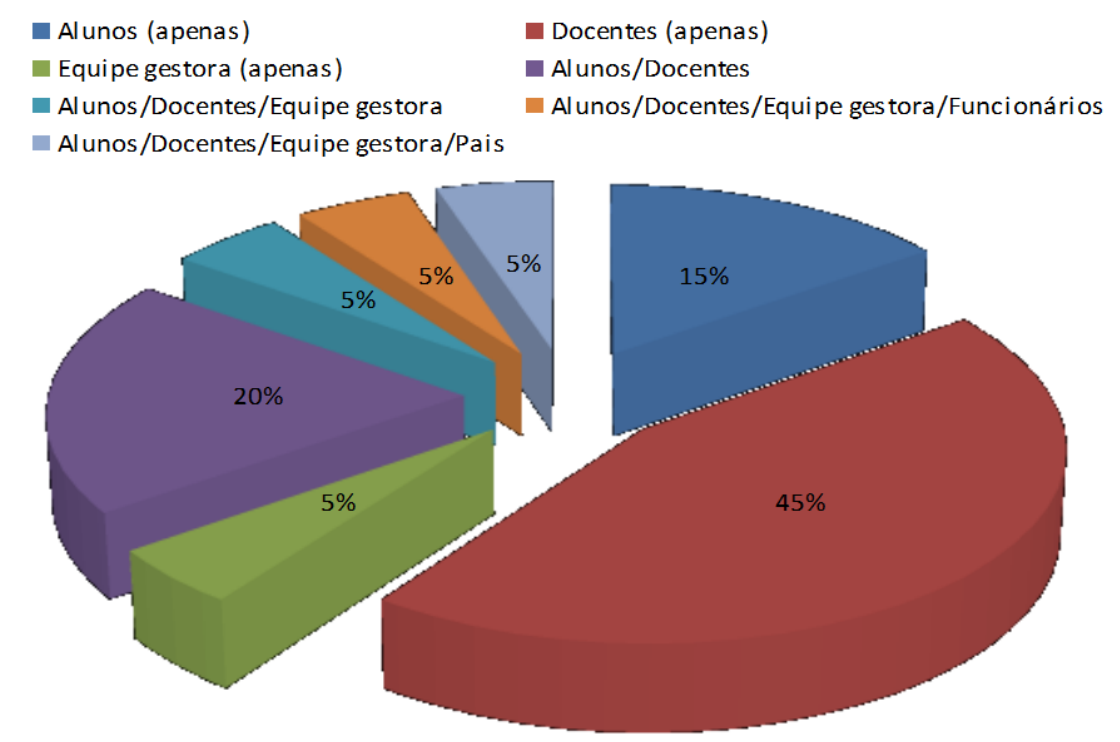

Gráfico 2. População envolvida

Em relação a população envolvida nas pesquisas, evidenciamos que o maior índice está representado pela categoria Docente apenas (45\%), seguido por Alunos/Docentes (20\%), Alunos apenas (15\%). As outras categorias: Equipe Gestora (apenas), Alunos/Docentes/Equipe gestora, Alunos/Docentes/Equipe gestora/pais, Alunos/Docentes/Equipe gestora/Funcionários, todos representados com $5 \%$ (cinco por cento).

Abordagem e Método de pesquisa 
Abordagem Qualitativa Abordagem Quanti-qualitativa

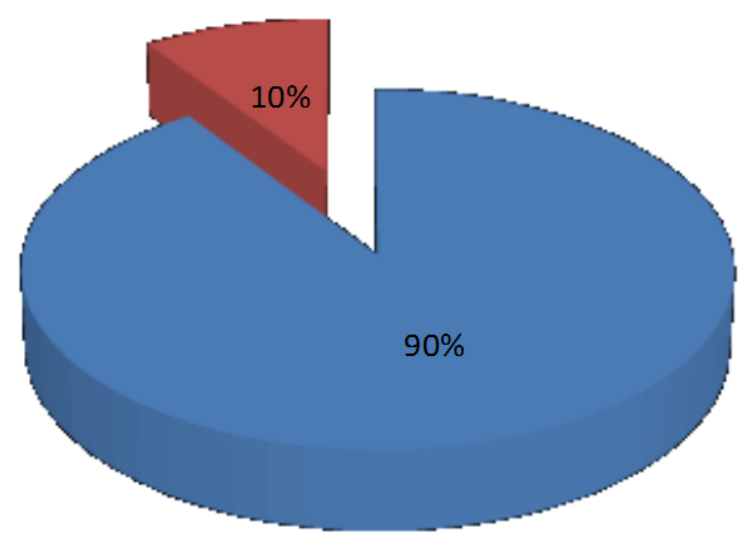

Gráfico 3. Abordagem de Pesquisa
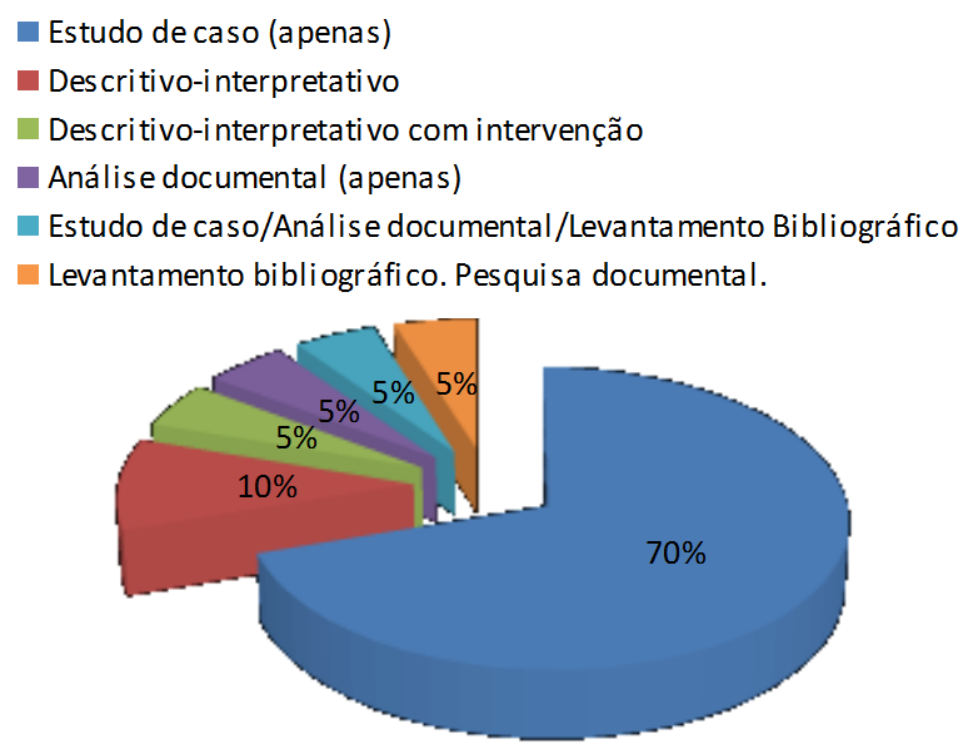

Gráfico 4. Método de pesquisa utilizado

Em relação aos gráficos 3 e 4 (Abordagem e método utilizados), verificamos que a maioria das pesquisas elegeram a abordagem qualitativa (90\%) associada ao método de Estudo de caso apenas (70\%), seguido pelo método Descritivo-interpretativo (10\%). Os $20 \%$ (vinte por cento) restante das pesquisas foram divididos em método Descritivo-interpretativo com intervenção, Análise Documental apenas, Estudo de caso/análise documental/Levantamento Bibliográfico e Levantamento bibliográfico/Pesquisa Documental, todos com índice de 5\% (cinco por cento).

\section{DISCUSSÃO}

Analisando os dados do gráfico 1 (Instituição envolvida), se somarmos a porcentagem da Escola pública (47\%) com a Escola particular infantil (5\%), verificamos que a maior parte das pesquisas (52\%) assumiram o ensino básico e suas questões como foco de suas pesquisas. 0 restante das pesquisas (48\%) representa a soma das pesquisas que elegeram o ensino superior como instituição dileta. Esta predileção é confirmada pelo gráfico 2 (População envolvida), que evidencia que $80 \%$ (oitenta por cento) das pesquisas contou com a colaboração de alunos e docentes das instituições envolvidas. Uma leitura conjunta dos dois gráficos, aponta a forte 
relação das pesquisas desenvolvidas em 2012 no programa de pós-graduação com o ensino básico e com binômio central (aluno e professor).

Esta relação sugere que as pesquisas desenvolvidas neste período influenciaram de modo direto e indireto nas relações de aprendizagem desenvolvidas em sala de aula, especialmente no ensino público. Outro aspecto a ser aprofundado é o efeito formativo nos profissionais de ensino da região (que abrange três estados do Brasil: SP, MS, PR), exercido pelo programa e que repercute diretamente na sala de aula e/ou nos processos de gestão escolar.

Sobre a abordagem e métodos de pesquisa (gráficos 3 e 4), a predileção pela abordagem qualitativa (90\%) indica a influência do conjunto das pesquisas realizadas no campo das ciências humanas em geral e no campo educativo, em particular, com uma forte tendência hermenêutica e fenomenológica, assim como uma certa aversão a abordagem quantitativa, na medida em que esta não abarcaria certos objetos, diletos nas pesquisas deste campo, quiçá por restringir seu alcance hermenêutico e fenomenológico.

\section{Conclusão}

A análise da produção discente, como ferramenta de autoavaliação, pode oferecer alguns indicativos que permite um melhor delineamento do programa como um todo, bem como apontar algumas relações importantes nos processos decisórios, em vista dos novos projetos de pesquisa discente.

De modo geral, ao analisarmos as dissertações do Programa, defendidas no período de 2012, com o intuito de mapear a distribuição das dissertações, evidenciamos a forte relação dos projetos desenvolvidos no programa com a escola básica e seus atores principais (alunoprofessor). Em relação a abordagem e metodologias de pesquisa adotadas, confirmamos uma tendência metodológica desenvolvida nas ciências humanas em geral, acentuadamente hermenêutico e fenomenológico.

\section{REFERÊNCIAS}

DIAS SOBRINHO, José. Avaliação da educação superior. Petrópolis: Vozes, 2000. . Avaliação: políticas educacionais e reformas da educação superior. São

Paulo: Cortez, 2003. 198p.

LUDKE, M. e ANDRÉ, M. Pesquisa em educação: abordagem qualitativa. São Paulo: EPU, 1986.

MARQUEZINE Maria Cristina e TRAMONTINA, Viviane Maroneis. Produção científica dos alunos egressos do curso de especialização da Universidade Estadual de Londrina. Revista Brasileira de Educação Especial. Vol. 12, no 1, Marília, jan/abr. 2006.

MASETTO, Marcos. Autoavaliação em cursos de pós-graduação. Campinas-SP: Papirus, 2004.

PAIVA, A. M. Rumos e perspectivas do egresso do programa de pós-graduação stricto-sensu em educação PUC-Campinas (1993-2004). Programa de Pós-Graduação em Educação, PUC-Campinas, 2006.

PENNA FIRME, T. Mitos na avaliação, diz-se que...in Meta: Avaliação. Rio de Janeiro: v.1.n.1 pp110.jan/abr 2009.

QUEIROZ, Fernanda Mendes e NORONHA, Daisy Pires. Temática das dissertações e teses em ciência da informação no Programa de Pós-Graduação em Ciências da Comunicação da USP. Ciência da Informação. vol.33, no 2, Brasília, maio/ago. 2004. 